\title{
Third-Party Logistics Providers in the Digital Age: Towards a New Competitive Arena?
}

\author{
Erik Hofmann ${ }^{1, *}$ (D) and Florin Osterwalder ${ }^{2}$ \\ 1 Chair of Logistics Management, University of St.Gallen, Dufourstrasse 40a, 9000 St. Gallen, Switzerland \\ 2 Lampe \& Schwartze KG Marine Underwriting, Herrlichkeit 5-6, 28199 Bremen, Germany; \\ f.osterwalder@lampe-schwartze.de \\ * Correspondence: erik.hofmann@unisg.ch; Tel.: +41-71-224-7295
}

Received: 4 September 2017; Accepted: 1 November 2017; Published: 4 November 2017

\begin{abstract}
This paper looks at the impact of digitalization on third-party logistics (3PL) business models. An eclectic framework for the analysis of digital disruptions in service industries is elaborated by linking Porter's five forces to insights from research on digitalization and innovation. Applying this framework to the business field of 3PL reveals that logistics service providers face significant digital hardship from new technologies such as autonomous vehicles and 3D printing as well as from platform-based business models and the sharing economy. We see the following changes in the competitive arena: First, 3PLs focusing on standard services may lose significant market share in the near future. Second, management-related 3PL activities seem to be increasingly offered by new external competitors, which may downgrade 3PLs to simple forwarders. Third, digitalization enables the forward or backward integration of 3PL customers and suppliers when they establish their own services. In addition to its threats, the opportunities of digitalization for 3PLs are discussed. These include the customization of standardized logistics services, the provision of cloud logistics services, platform-based asset and logistics infrastructure sharing, the "physical internet" as a future transportation system and the adoption and integration of 3D printing into existing 3PL business models.
\end{abstract}

Keywords: third-party logistics (3PL); logistics; digital disruptions; industrial economics; e-business; digitization

\section{Introduction}

Over the past several decades, logistics activities have increasingly been sourced out to specialized third-party logistics providers (3PLs) [1]. In recent years, however, 3PLs have increasingly been challenged by new disruptive business models and digital technologies. For example, platforms such as Cargomatic [2] and Uber Freight [3] enable cost-efficient, real-time, on-demand arrangements of transports that cut into the domain of logistics services. E-commerce providers such as Amazon, which used to be a business partner to 3PLs, has started building up its own online-based logistics solutions [4]. Similarly, vehicle manufacturers have started to leave their traditional business field and provide their own digitalized fleet management and mobility services, which used to be domains of 3PLs as well. As pointed out in a study by the consultancy company Oliver Wymann, logistics start-ups from the USA and Asia with high financing volumes are transforming the entire logistics industry [5]. This puts significant pressure on traditional logistics markets such as Germany, Sweden and the Netherlands, with their established market players [6]. Experience from other industries such as travel and retail shows that digital disruptions may change entire markets within a very short time. In the course of these changes, business models that have been dominant for decades are replaced by new ones [7]. 
Despite the significance of this topic, the impact of digitalization on logistics service providers has barely gained any attention in the literature. So far, digital disruptions in logistics have mainly been addressed by practitioners - that is, research departments of logistics service providers (LSPs) and consultancy companies. For instance, the Logistics Trend Radar by DHL [8] names new technologies and business models evolving in logistics. McKinsey \& Company [9] investigates the transformation of commercial transport by 2025 and Deloitte [10] released a study on the impact of the sharing economy on transportation. A further paper by DHL [11] outlines implications of 3D printing for future supply chains and logistics. Academic literature on digitalization in logistics focuses on more specific digitalization-related topics. For example, Harris et al. [12] describe the importance of information and communication technologies for intermodal transport and address the topic of slow technology adoption in transportation. Delfmann et al. [13] derive strategic implications for LSPs from emerging e-commerce activities. Kim et al. [14] take a strategic approach and give an outline on competitive advantages achieved by 3PLs through the use of information technologies. Moreover, platform businesses in logistics is a topic addressed by several authors. Varella and Buss Gonçalves [15], for example, focus on the design of the strategic planning of logistics platforms. Cheng and Wang [16] look at the potential contribution of logistics and transport platform data to supply chain management. Finally, a more general perspective on digitalization in logistics is provided by Nguyen [17], who sheds light on different aspects of e-business and the internet in logistics. However, the topic of digital disruptions in the logistics industry and corresponding impacts on 3PL has not been addressed in academic literature yet.

Against this background, the main objective of this paper is to assess whether digitalization with its disruptive potential threatens the position of 3PLs as important players in the logistics services industry or their current business models. The basic research question (RQ) that this paper aims to answer can be formulated as follows:

- Will the disruptive potential of digitalization jeopardize the viability of current 3PL business models?

Answering this research question involves the consideration of the options available to 3PLs for reacting to digital disruptions. Thus, the following sub-research-question (SRQ) is also addressed:

- What options does digitalization offer 3PLs?

In answering the research questions, we follow a qualitative and conceptual research approach consisting of the following steps, which represent the structure of this paper: First, in Section 2, a systematic framework for the analysis of digital disruptions in service industries is developed by linking Porter's five forces [18] to theories from research on digitalization and innovation. The framework elaboration is based on academic literature. In Section 3, the elaborated framework is applied to the 3PL industry through an analysis of practical examples of new digitally based logistics technologies and business models. Information on the examples was obtained from the internet and the effects of these examples on 3PL were discussed in team sessions. Drawing on the results of the framework application, the main digital threats for 3PL are identified and discussed in Section 4. In the final section (Section 5), digital opportunities for 3PL are outlined in a literature-based elaboration of countermeasures against the identified threats.

The contribution of this paper is threefold: first, we present a structured theory-based framework for the analysis of digital disruptions in service industries. Second, we provide a literature-based structuring of current generic 3PL business models. Third, a new competitive arena involving opportunities from digitalization in the 3PL industry is elaborated.

\section{Theoretical Background and Framework Elaboration}

\subsection{Theoretical Background}

In line with the above research questions, this paper adopts viewpoints from industrial economics, which can be defined as "the study of firms, industry and markets" [19]. Industrial economics looks at 
the behavior and organization of firms and simultaneously takes into account market and industry competition and economic policy [20] and thus significantly impacts the strategic management of companies [21]. One central framework linking industrial economics to business strategy is Porter's five forces [18]. The basic idea of the five forces approach is that in order to achieve long term profitability, a company has to respond strategically to competition. However, to correctly assess competition and arrive at appropriate strategies, it is insufficient merely to consider direct rivals within one's own industry. Rivalry among existing competitors is only one of the five forces that shape competition. The four additional forces are as follows [22]:

- Threats of New Entrants. New entrants bring more capacity and the desire to gain market share. This puts pressure on prices and raises costs as well as the required investment rate.

- Bargaining Power of Suppliers. Suppliers' bargaining power leads to increases in the prices of sourced products and services, a limitation of services and a limitation of quality. Costs are passed on to industry participants.

- Bargaining Power of Buyers. The counterpart of suppliers' power, buyers' power gives them the strength to push down prices, demand high quality and demand special services.

- Threat of Substitute Products or Services. Substitutes perform the same or a very similar basic function as the product or service of the focus industry and thereby become interchangeable with them.

In addition, digitalization has become an increasingly significant factor of competition in various industries. On the business side, the increasing significance of digital technologies can be attributed to the changing role of information technology (IT). Originally, IT was mainly used for support functions such as inventory or finance. Later, business processes were digitalized using customer relationship management (CRM) applications and enterprise resource planning (ERP) systems within and between companies. The main focus in this era was on efficiency and costs [23]. Today, however, IT capabilities are used for the development of new products and services, as well as for the innovation of business models [24]. An important driver of digitalization is the rapidly increasing worldwide coverage of broadband internet, which makes it possible to conduct business over the internet (e-business) [7]. In recent years, the use of mobile devices (e.g., smart phones), social media, cloud solutions and analytics have become important drivers of digital transformation [25] and have made digital technologies omnipresent. From a customer perspective, offers such as e-commerce, e-banking and online booking have become standard services in today's industries [23]. These developments offer benefits for customers especially [26]. On one hand, markets are more efficient and prices are reduced. On the other hand, almost every sort of niche product is available online. In addition, digitalization has given rise to entire new models of consumption, such as the sharing economy [27]. In this context, three waves of consumption digitalization can be distinguished. First, the online shopping wave, which is characterized by the replacement augmentation of brick-and-mortar stores by digital stores and digital payment. Second, the participatory consumption wave, which is characterized by sharing and collaboration among consumers, which evolve into "prosumers," a combination of both producers and consumers. Third, the virtual consumption wave, which is characterized by virtual or non-real goods [28].

As can be seen from industries such as retail, digitalization (and the internet) continuously intensifies competition [29]. Despite these significant changes, the core concept of Porter's five forces remains valuable and applicable [30]. However, insights from the fields of digitalization and innovation need to be considered and the forces must be adjusted accordingly. This gap constitutes the basis for the development of the analysis framework elaborated in the following section.

\subsection{Theoretical Analysis Framework}

In the course of the framework development, each of Porter's five forces was linked to an individually chosen piece of theoretical reasoning from innovation and digitalization research. Figure 1 provides an overview of the framework in general. 


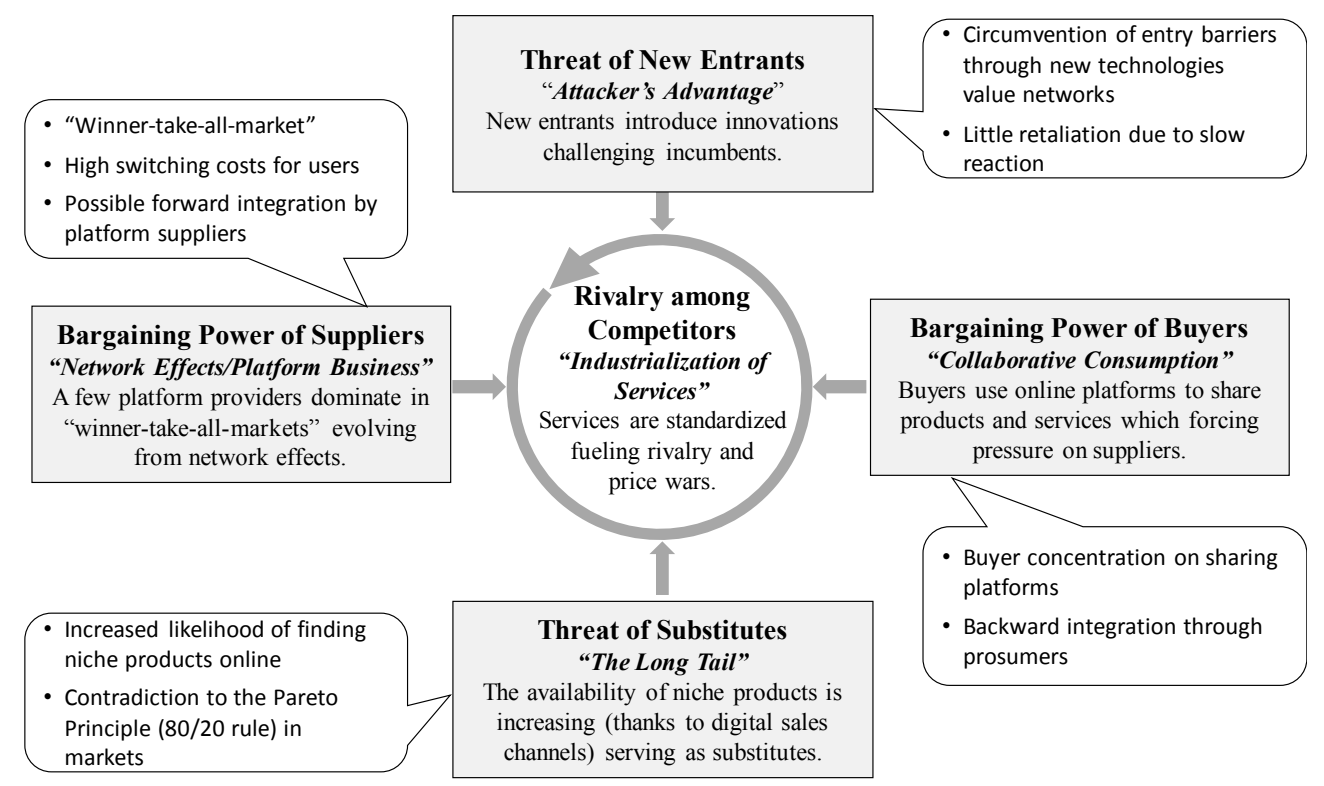

Figure 1. General framework for the analysis of digital disruptions in service industries.

\subsubsection{Threat of New Entry and the "Attacker's Advantage"}

The threat of new firms that enter a market depends on two main factors [22] (p. 26): existing entry barriers, which are advantages that incumbents have and the retaliation that new entrants can expect from incumbents.

To successfully enter an industry, new entrants need to overcome entry barriers and avoid retaliation from incumbents. Regarding digitalization, this can be achieved by making use of its disruptive potential. From a theoretical point of view, the disruptive potential of digitalization can be explained by the "attacker's advantage." This thesis states that firms bringing new technologies to markets have an advantage to which incumbents have to react [31,32]. Modis [33] explains the attacker's advantage by applying theories from biological sciences to business. Two species living in the same habitat inhibit each other's growth since they compete for food. However, one species can outgrow its competitor if it has a special capability which allows it to adapt better to the prevailing circumstances and thus gain more food. Applying this concept to business gives an explanation why new companies that deliver unique benefits to customers gain more market share. Moreover, incumbents struggle to defend the attack since they tend to lag behind.

Christensen and Rosenbloom [32] (pp. 235-242) explain the attacker's advantage in more detail and have identified three factors: Technological paradigms, organizational dynamics and value networks. The first factor looks at the relation of capabilities between new and old technologies. Incumbents can run into trouble as they tend to struggle with gaining capabilities to compete with new technologies. The second factor considers managerial processes and changes within organizations. Based on their past successes, incumbents tend to have rather solid structures with an established culture and fixed problem-solving patterns. These circumstances impede an appropriate reaction towards attackers using new technologies. The third factor encompasses that incumbent firms lead in their established value networks but often fail to satisfy customer needs in emerging value networks. However, these emerging value networks hold large potentials for future profits. Further support for the third point was presented by Christensen and Bower [34], who argue that new technologies from emerging markets are ignored by large incumbents. However, new technologies have the potential to invade the mainstream markets, which gives attackers an advantage over established market players. 


\subsubsection{Bargaining Power of Suppliers and "Network Effects"}

Suppliers are powerful, if they capture most of the value for themselves by actions such as raising prices or reducing services [22] (p. 29).

In the digital age, a company operating a platform that serves as an intermediary between two user groups can build up significant market power by profiting from network effects. Network effects arise when the attractiveness of a platform to users grows with the number of its users. For example, if we assume two groups of users interacting on a platform, the attractiveness of the platform for one user group grows with the size of the other group. This phenomenon is referred to as direct network effect. Network effects can also be indirect. Indirect network effects arise if users anticipate several complementary products and services that grow with the number of users [35].

In view of Porter's five forces, network effects fuel the bargaining power of platform suppliers. To be able to profit from network effects, platform providers have to gather as many users as possible. At the same time, platform providers face increasing returns on scale. The combination of both factors can result in market inefficiencies, as the market is likely to be dominated by a few very large platform suppliers. This phenomenon is commonly referred to as a "winner-take-all market" [36,37], which is tantamount with a massive concentration of platform suppliers. Moreover, the offers of the remaining suppliers have to be differentiated so that they can outperform competing platform providers [36]. Since most customers do not have a large choice of other providers, platform substitutes are barely available. Thus, network effects provide platform operators with significant market power, which includes the threat of forward integration as new services can easily be provided to a large customer base.

\subsubsection{Bargaining Power of Buyers and "Collaborative Consumption"}

The bargaining power of buyers is the counterpart of the supplier power described above. Thus, buyers are powerful if they can force prices down or demand more services [22].

Similarly, in their dealings with suppliers, buyers can build up power through platform businesses. The power of buyers is fostered through the phenomenon of collaborative consumption, which is also referred to as the "sharing economy." In this type of consumption, buyers do not strive to own a product (or a service) but pay for temporary access or joint use [38]. In general, the sharing economy creates the possibility of disintermediation, a collaborative utilization of excess capacities and increasing productivity. It has spread over a variety of industries such as room sharing, energy sharing and car sharing and has a large global growth potential [39]. Barnes and Matsson [27] (p. 200) define collaborative consumption as "the use of online marketplaces and social networking technologies to facilitate peer-to-peer sharing of resources (such as space, money, goods, skills and services) between individuals who may be both suppliers and consumers." The crucial feature of this definition is that the role of consumers is blurred with that of producers [40]. This significantly enlarges the potential for backward integration, since buyers may entirely replace suppliers. Moreover, sharing reduces the amount of manufactured goods and produced services. This enables buyers to build up pressure on suppliers and push prices for products and services down [27]. In addition, the increased collaboration of buyers via online marketplaces can be considered buyer concentration, in which buyers are provided with a larger market power and increased leverage against suppliers.

\subsubsection{Threat of Substitutes and the "Long Tail"}

A substitute performs the same function as the original product by different means. In many cases, substitutes are of an indirect nature and appear completely different from the original product or service. The threat of substitutes is especially high when the alternative offers an attractive price-performance ratio and when the switching costs for customers are low [22] (p. 31).

In the digital age, the threat of substitutes is especially increased by the "long tail" phenomenon. The long tail can be basically described as "selling less of more" [41,42]. In the era of digitalization 
and internet business, almost every conceivable product can be found on online marketplaces. Consequently, niche products that are barely available in brick and mortar stores make up an increasing proportion of sales. This especially contradicts the classical Pareto Principle, according to which $20 \%$ of products in a market generate $80 \%$ of sales [43], which changes market laws entirely. Different explanations for the long tail phenomenon have been given. Brynjolfsson et al. [44] differentiate between supply-side and demand-side drivers. On the supply side, the internet inter alia offers a larger product selection, which is made possible by new means such as low-cost virtual shelves, demand-tailored products and electronic delivery. On the demand side, customers' search costs are reduced by means such as efficient information tools, recommendation functions and specialized communities. In conclusion, since a constantly increasing number of products and services are available online, the likelihood of finding substitutes for existing products and services is growing constantly.

\subsubsection{Rivalry among Existing Competitors and the "Industrialization of Services"}

Rivalry among competitors in an industry can take many forms, such as price discounting or new product introduction and significantly limits profitability. The impact of rivalry on an industry mainly depends on two factors-the intensity of rivalry and the basis of competition. The most destructive type of rivalry is the price war [22].

In the realm of services, digitalization has been triggering various innovations. One important tendency is the "industrialization of services," which stands for the industry-like standardization of most services. Similar to manufactured mass products, services are split into industrial components. From a customer point of view, this standardization ensures certain levels of service quality as well as predictable service products [45]. From a company point of view, service industrialization aims to implement lean structures and manage information-intensive services. This improves the flexibility, productivity and quality of the service business as a whole [46]. For customers, uniform quality and service standards bear clear benefits. For service providers, however, the standardization in particular renders their services exchangeable and thus vulnerable for competition and outsourcing [47]. Referring to Porter's explanation of the rivalry among competitors, it can be concluded that the industrialization of services leads to an equalization of provided services. This intensifies rivalry among service providers and simultaneously fuels price competition. The latter is even further intensified by the fact that services are perishable by their very nature and tend to have high fixed costs since service providers have to provide necessary service capacities.

Finally, as described by Porter, analyzing an industry by means of the five forces provides a basis for anticipating and influencing competition [22]. Analogously, the developed analysis framework allows one to identify and anticipate possible digital disruptions in a service industry. Understanding the disruptive mechanisms helps in identifying the main industry threats. In turn, these identified threats then serve as basis for the identification of evolving digital opportunities.

\section{Analysis of the 3PL Industry}

\subsection{Analysis Approach}

Following Porter's suggestion [22], our framework is applied to the 3PL industry in a procedure consisting of the following four phases:

1. Industry Definition. This first phase encompasses the definition of the term 3PL as well as a description of current 3PL business models and corresponding value chain activities. The elaboration of 3PL business models is based on a structured literature review.

2. Industry Screening and Practical Examples. The second phase is the core part of the analysis. The 3PL industry is screened by applying each of the five forces in conjunction with its theoretical reasoning. For each force-theory combination, the following three sub-steps are carried out: 
(a) Practical Examples Presentation. First, practical examples of the respective force-theory combination are presented.

(b) Theoretical Reasoning. Second, the disruptive mechanisms behind the practical examples are explained on the basis of the identified force-theory combinations.

(c) Impact Analysis. Third, potential impacts of the practical examples on the 3PL value chain are outlined. For the sake of structuring the analysis, three possibilities for impacts on activities of the value chain are distinguished:

- Substitution. The activity is likely to be substituted by the described digital technology or business.

- Complement. The activity is likely to be complemented by the described digital technology or business.

- No Influence. The activity is not influenced or is only barely influenced by the described digital technology or business.

3. Identification of Threats. In the third phase, the results are summarized and the main threats for 3PL are outlined.

4. Identification of Opportunities. In the fourth phase, possible options arising from digital technologies for 3PL are derived from the practical examples and identified threats.

To achieve a holistic approach, phases 2, 3 and 4 of the industry analysis were carried out in the form of team discussions. We now represent the results of these discussions. For the sake of clarity, the remainder of this paper is structured as follows: phases 1 and 2 of the industry analysis are described in Sections 3.2 and 3.3. The threat identification is presented in Section 4 and the identification of opportunities is described in Section 5.

\subsection{Industry Definition: 3PL and Corresponding Business Models}

In general, LSPs can be defined as companies that carry out logistics services on behalf of others [13] (p. 204). Hofmann and Lampe [48] differentiate among the following LSP clusters:

- Carriers (three types: rail, truck, sea) are the most basic form of LSP and focus on the physical movement of goods by a certain transport mode.

- Currier, express and parcel (CEP) providers offer standardized services that can be customized to a certain degree.

- 3PLs have by far the largest activity scope and provide transportation as well as additional customized logistics-related services.

- 4PLs develop entire supply chain and logistics management solutions for customers but they do not have their own physical assets. All physical activities are outsourced to other LSPs (see also [49]).

This paper focuses on 3PLs, as 3PLs play a central role in the logistics service industry and provide a wide range of services, which have several weak points potentially susceptible to digital disruption. A uniform scientific definition for 3PLs does not exist [50]. Therefore, the following definition for 3PLs was elaborated by extracting the core points from definitions in academic journal articles [51] (p. 29), [52] (p. 59), [53] (p. 26), [54] (p. 93): Third-party logistics (3PL) providers are companies that provide transportation and further logistics-related services to other companies (in B2B relationships) and private customers (in $\mathrm{B} 2 \mathrm{C}$ relationships).

In accordance with the $R Q$ and the described application procedure, the next step is to identify currently existing 3PL business models. A business model can be defined as "the rationale of how an organization creates, delivers and captures value" [55] (p. 14). For this purpose, a review of the literature on 3PL business models and 3PL service ranges was conducted.

We elaborated a portfolio of four generic 3PL business models as shown in Figure 2. The portfolio is based on the 3PL clusterings proposed by Alfredsson and Hertz [56], Berglund et al. [52] and 
Delfmann et al. [13]. The portfolio also refers to the two generic 3PL business models-3PL lernstatts and 3PL factories-identified by Prockl et al. [57] and includes the service internationalization strategies of 3PL described by Lemoine and Dagnaes [58].

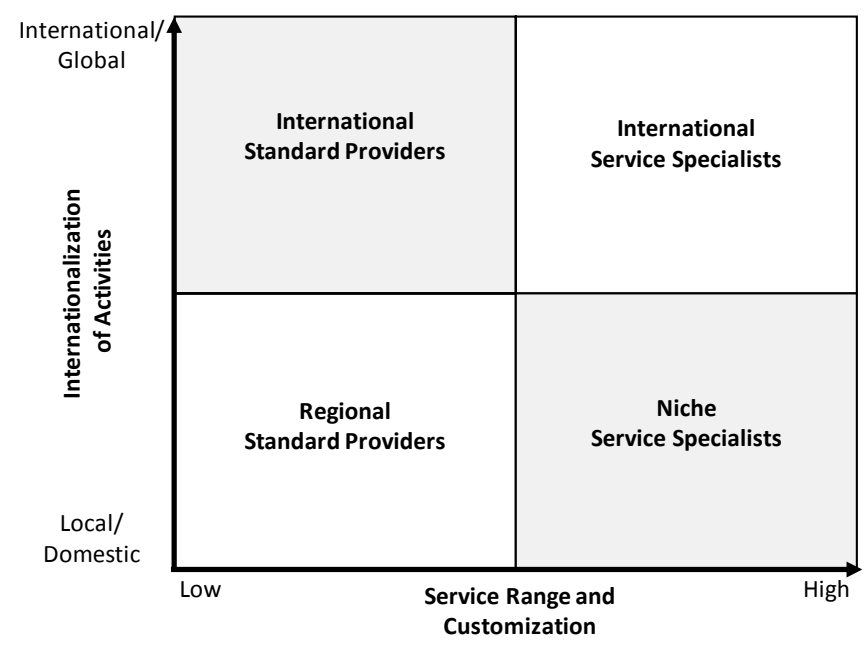

Figure 2. Portfolio of generic third-party logistics (3PL) business models. The business models are differentiated from each other by the provided service range and corresponding customization (horizontal axis) as well as by the degree of internationalization of activities (vertical axis).

The generic 3PL business models can be described as follows:

- Standard regional 3PLs render standardized short-haul transportation and transportation management services within certain regions such as cities, states, or countries. While such companies also offer warehousing and inventory management, extensive additional services are not provided. As this business model represents the most basic type of 3PL, it is similar to that of pure forwarders. In view of digitalization, standard regional 3PLs may provide basic services such as track-and-trace or digital order processing. However, resources and capabilities for the implementation of advanced digital services and technologies are limited.

- Niche service specialists operate on a regional level and provide transportation services, warehousing and inventory management services and other services. Firms using this business model are rather small, have specialized knowledge and develop solutions for business customers (B2B) with special service requirements. Similar to standard regional 3PLs, niche service specialists provide a limited range of digital services that are tailored to the service niche.

- Standard international 3PLs are medium-sized or large companies that provide mainly long-haul transportation services as well as warehousing and inventory management services in international networks. To achieve international and global service coverage, companies applying this business model provide different modes of transportation (road, rail, air and sea). For this purpose, standard international 3PLs may subcontract smaller local carriers and book slots on oceangoing ships and airplanes. Due to their size and the larger distances they handle, their transportation and warehousing activities are rather complex and include operations such as crossdocking and terminal handling. Standard international 3PLs provide a set of basic digital services, such as track-and-trace, electronic data interchange (EDI) with customers and digital transportation management solutions.

- International service specialists offer global transportation services, global warehousing and inventory management services and a large range of additional services. Companies with this business model focus on business customers and provide global supply chain management solutions, including the development of tailored services. This is the most complex 3PL business model and is closely related to fourth-party logistics (4PL). Compared to the other three business 
models, international service specialists provide the most complex digital solutions. These include not only EDI and track-and-trace but also services for the management of supply chains.

In line with the business model definitions of Osterwalder and Pigneur [55], the 3PL business models identified above can be compared to each other in terms of their focus on activities along a suggested 3PL value chain consisting of five steps as shown in Figure 3. The 3PL value chain is further specified in Table 1, which describes the main activities for each step.

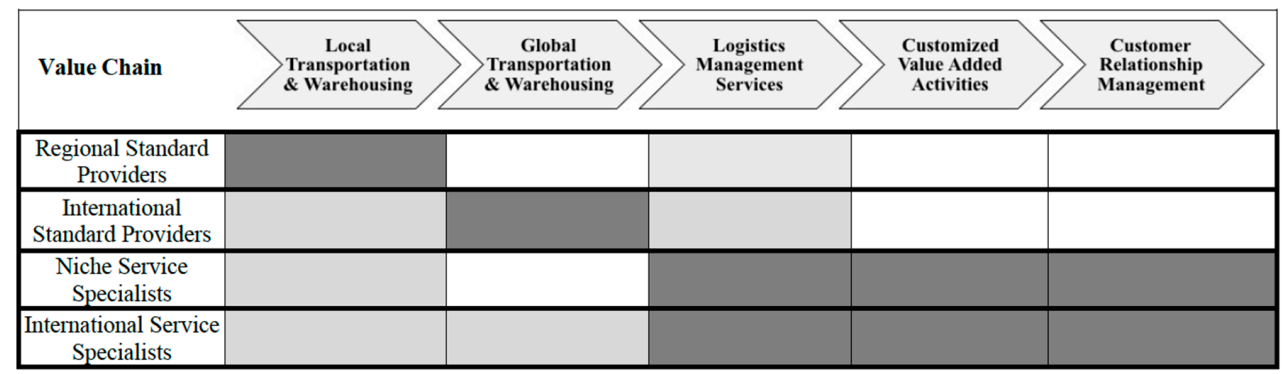

Figure 3. Activities of generic 3PL business models along the logistics service value chain. Dark grey fields indicate main activities, light grey fields indicate supplementary activities and white fields indicate that the value chain step is not covered by the respective business model.

Table 1. 3PL value chain activities.

\begin{tabular}{|c|c|}
\hline Value Chain Step & Main Activities \\
\hline \multirow{4}{*}{$\begin{array}{l}\text { Local Transportation and } \\
\text { Warehousing }\end{array}$} & Local Cargo Consolidation: local gathering of individual shipments \\
\hline & Regional Haulage: transport between two regions (national, by truck) \\
\hline & Local Cargo Distribution: distribution of shipments to customers \\
\hline & Warehousing: storage of goods in warehouses \\
\hline \multirow{5}{*}{$\begin{array}{l}\text { Global Transportation } \\
\text { and Warehousing }\end{array}$} & Regional Cargo Consolidation: regional gathering of shipments \\
\hline & Main Haulage: international main transport between two hubs (multimodal) \\
\hline & Regional Cargo Distribution: regional distribution of shipments \\
\hline & Warehousing: storage of goods in warehouses and terminals \\
\hline & Chartering: subcontracting of local carriers, vessels, airplanes \\
\hline \multirow{3}{*}{$\begin{array}{l}\text { Logistics Management } \\
\text { Services }\end{array}$} & Consulting Services: development of customized logistics concepts \\
\hline & $\begin{array}{l}\text { Transportation Management: planning, monitoring and conducting transports; handling and } \\
\text { storage of goods }\end{array}$ \\
\hline & IT Services: services such as track and trace, API and EDI \\
\hline \multirow{3}{*}{$\begin{array}{l}\text { Customized } \\
\text { Value-Added Services }\end{array}$} & Packaging and Labelling: packing, commissioning and labelling of goods on behalf of shippers \\
\hline & Manufacturing Services: product assembly and contract manufacturing on behalf of shippers \\
\hline & Special Transports and Handling: transportation and handling of special goods \\
\hline \multirow{3}{*}{$\begin{array}{l}\text { Customer Relationship } \\
\text { Management }\end{array}$} & Order Processing: acting as interface between shippers and customers \\
\hline & $\begin{array}{l}\text { Administrative Support: support for shippers and customers with tasks such as billing and } \\
\text { claims handling }\end{array}$ \\
\hline & On-demand services: arrangement of service times according to customer needs \\
\hline
\end{tabular}

As can be seen from Figure 3 and Table 1, the various 3PL business models have different foci along the 3PL value chain. While standard providers (regional and international) focus mainly on the physical movement of goods, service specialists (niche and international) cover almost the entire value chain and concentrate on value-added and immaterial services.

\subsection{Screening of the 3PL Industry}

Phase 2 of the application of the framework to the 3PL industry can now be described. Figure 4 provides an overview of the industry analysis by showing the practical examples analyzed for each force-theory combination. 


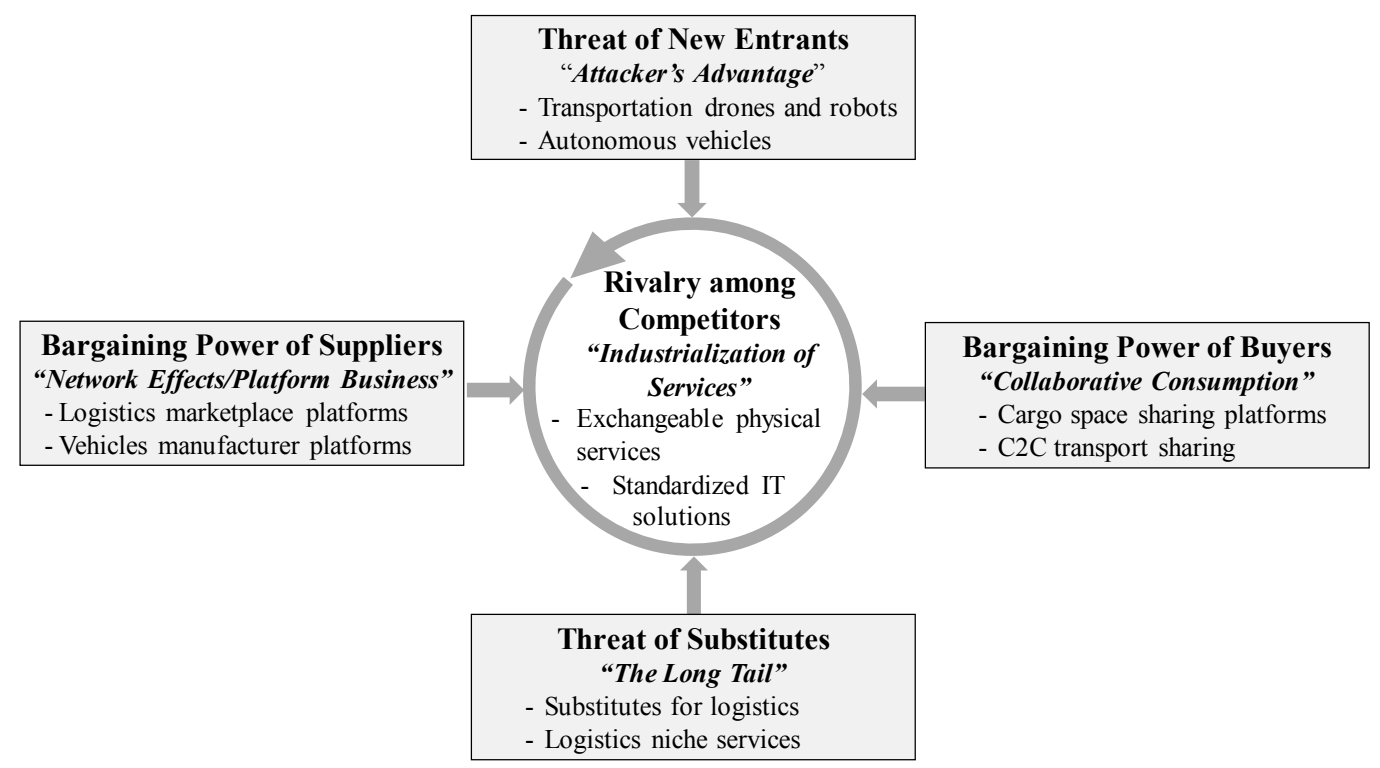

Figure 4. Screening of the logistics service industry in the new digital age. The identified force-theory combinations build up a new competitive arena for 3PLs, as logistics service providers are under pressure from all "sides" of the framework.

\subsubsection{Threat of New Entrants through the Attacker's Advantage}

\section{(a) Practical Examples}

Disruptive logistics technology developments can be found especially plentifully in the field of physical goods movements. Several projects in this field aim to use drones and robots for locally transporting small cargo units and for handling in warehouses. Moreover, various larger autonomous transport vehicles are also under development. Tables 2 and 3 give an overview of practical examples of both technologies.

Table 2. Practical examples of autonomous transportation vehicles.

\begin{tabular}{l} 
Autonomous Vehicles for Transportation \\
\hline Uber Freight/Otto Self-Driving Trucks \\
Otto is a start-up specializing in hardware and software systems for self-driving trucks. The company does not build its \\
own trucks but develops a system that can be retrofitted in existing trucks. In 2016, the first autonomous transport of \\
beer using a truck equipped with Otto's system was successfully carried out in the US. Although the trucks still require \\
drivers for safety reasons, the future goal is to build completely autonomous vehicles [59]. Otto has been acquired by \\
the transportation platform Uber Freight. \\
\hline Daimler Freightliner Inspiration \\
The Daimler Freightliner Inspiration is an autonomous truck constructed by Daimler Benz. The vehicle was given a \\
road approval in the US state of Nevada and is equipped with a specially developed highway autopilot system. The aim \\
is to achieve series production maturity of the technology by 2025 [60]. \\
DNV GL ReVolt \\
DNV GL ReVolt is a fully autonomous, emission-free short-sea vessel currently being developed by the ship \\
classification society DNV GL. The vessel has a service speed of 6 knots, a service range of around 100 nautical miles \\
and a cargo capacity of around 100 twenty-foot standard containers. One driving force of the development of this vessel \\
is to ease the transition of traffic in Europe from roads to waterways [61]. \\
\hline
\end{tabular}


Table 3. Practical examples of the use of drones and robots in local transportation and warehousing.

\begin{tabular}{l} 
Drones and Robots for Local Transportation and Warehousing \\
\hline Amazon Prime Air \\
Amazon Prime Air is a parcel distribution service currently being developed by the e-commerce company Amazon. \\
The aim is to deliver parcels to Amazon Prime customers by dispatching flying drones within 30 minutes of a product's \\
being ordered. The drones navigate autonomously using sensors and have a working load of around 2.5 kilograms. \\
The possible operating range is approximately 10 miles [62]. \\
\hline Alphabet (Google) Project Wings \\
As Amazon Prime Air, the Alphabet (Google) Project Wings aims to develop a delivery system for parcels via flying \\
drones. In addition to air-based delivery, the plan is to provide ground handling of parcels by robots on wheels. So far, \\
the system has been successfully tested in Australia and is already approved for six sites (cities) in the USA. Further \\
tests are supposed to take place in 2017 [63]. \\
\hline Swiss Mail Robots \\
A project that was launched by the Swiss Post, Mail Robots aims to expand the service portfolio with same-day and \\
same-hour deliveries using robots on wheels. In addition to mail delivery, these robots can also be used for urgent home \\
deliveries of medications or home deliveries of foodstuffs. The robots can carry approximately 10 kilograms and have \\
range of around 6 kilometers [64]. \\
\hline Fetch Robotics \\
Fetch Robotics is a company specializing in the development and construction of autonomous mobile robots, material \\
handling and data collection. The company successfully developed several fetch robots used for automated handling of \\
materials and goods with different shapes and sizes in warehouses [65]. \\
AutoStore \\
AutoStore provides a new, completely autonomous warehousing system. Goods are stored in bins that are stacked in \\
large, multi-level grids. Robots move on rails mounted on top of the grids and store the bins autonomously. The goods \\
and bins enter and leave the warehouse at ports, which serve as an interface between robots and staff. The system can \\
also be installed at older warehouses [66].
\end{tabular}

\section{(b) Theoretical Reasoning}

Drones, robots and autonomous vehicles represent completely new technologies in the logistics service industry. Until now, local transportation has been mainly carried out by small trucks, delivery vans, or couriers (in the case of very small consignments). At the same time, international transportation is carried out by trucks, ships and aircrafts. While these classical transportation vehicles require manual operation, drones, robots and autonomous vehicles can be operated remotely by computers and navigate autonomously with sensors. Consequently, the disruptive potential of these technologies lies in efficiency through automation, which allows the cutting of significant costs and thus reduces entry barriers. The same points apply to warehousing, where the use of robots allows a reduction of costs and an increase in the efficiency of warehouse operations. Additionally, autonomous warehouse technologies may be combined with autonomous transportation technologies to create new, completely autonomous logistics systems.

Furthermore, these technologies allow companies to build up new value networks. In the case of e-commerce companies such as Amazon, drones enable the companies to expand their business model by establishing their own delivery services. This enhances the value proposition, as customers have the new opportunity to arrange an immediate delivery of purchased goods at any site within the range of drones (or robots). Conversely, deliveries arranged conventionally in cooperation with 3PLs often require a lead time of several days and the customer runs the risk of missing the delivery due to absence. The provision of one's own automated in-house transportation services reduces the e-commerce companies' dependence on logistics service providers. The same point holds true in the case of Google or Swiss Post. Both companies have the opportunity to enhance their value networks by establishing themselves as new suppliers of local transportation solutions tailored to demand.

Similarly, autonomous vehicles allow for the creation of new value networks. As the example of Otto's acquisition by Uber shows, autonomous vehicles provide the opportunity to enter the physical transportation market by means of a new technology. While Uber Freight currently operates as an intermediary between carriers and customers, its future aim is to expand the business model by operating its own fleet of autonomous trucks in combination with the freight booking platform. Similar 
developments are also conceivable for vehicle producers such as Daimler, which could establish its own autonomous transportation services in combination with freight platforms. Developments in this direction are already observable in the passenger car industry, where car manufacturers such as BMW [67] operate their own car-sharing fleets.

Finally, it has to be noted that none of the companies presented in the examples emerges from the field of 3PL. Instead, they come from other industries such as automotive (Daimler), e-commerce (Amazon) and mail service (Swiss Post) and develop technologies that are disruptive for the logistics sector. This can be viewed as support for the thesis that incumbents (in this case 3PLs) react slowly to technological disruptions.

(c) Value Chain Impact

Recent technology trends have the potential to substitute activities both in the field of local transportation and in that of warehousing, especially in the case of small cargo units (i.e., CEP). As autonomous vehicles are significantly larger, have a wider service range and are capable of carrying large amounts of cargo, they can substitute the main transportation leg (national and international). In addition, as can be seen from the examples of container terminals, the storage of goods also has the potential to be fully automated. Moreover, both of these technologies work with its own IT solutions, which allow them to arrange and manage transports more independently than similar services provided by 3PLs. This substitution effect is reinforced by the possibility of full transport automation.

\subsubsection{Supplier Power through Network Effects}

\section{(a) Practical Examples}

Two types of platform businesses are currently emerging in the logistics service industry: logistics marketplace platforms, which act as intermediaries between shippers and LSPs; and vehicle manufacturer platforms, which offer telematics-based data mining services such as fleet management for business customers. Practical examples are stated in Tables 4 and 5 .

\section{(b) Theoretical Reasoning}

Applied to the logistics service industry, platforms mainly serve as marketplaces for transports. Transports have hitherto been arranged through middlemen or agents. Conversely, logistics marketplace platforms enable direct interactions between shippers and LSPs (3PLs) and thus allow the parties to bypass such middlemen. The direct contact accelerates processes, saves costs and allows services to be customized. In addition, platforms often provide complementary IT services such as real-time track-and-trace, or functions for transport supervision and management. From a customer point of view, this increases the attractiveness of platforms and fosters indirect network effects. Through their role as intermediaries and IT service providers, logistics platform operators have the potential to develop both comprehensive industry knowledge and significant market power. This combination could enable platform operators to take over the role of classical actors in the logistics service industry (such as that of 3PLs) and herein lies the threat of forward integration. A first step towards forward integration by logistics platform operators can be seen in Uber's acquisition of Otto. This acquisition enables Uber to operate its own fleet that is managed and offered via its own transportation platform. As a result, Uber Freight would become a full LSP with a service range similar to that of 3PLs. Network effects play a special role in this case, as they lead 3PLs to increasingly depend on logistics platforms. Their dependence stems from the fact that an increasing number of potential clients (shippers) use such platforms. This in turn increases switching costs for 3PLs, as leaving a platform is tantamount to losing direct customer contacts. As can be observed in other platform business markets such as social media (Facebook) or e-commerce (eBay and Amazon), network effects may lead to markets with a small number of very large platform providers. It stands to reason that a similar outcome is possible in 
the case of logistics platforms, if a small number of platform operators manage to gather enough users from both sides-that is, from 3PLs and shippers.

Table 4. Practical examples of logistics marketplace platforms.

\begin{tabular}{l} 
Logistics Marketplace Platforms \\
\hline Uber Freight \\
Uber Freight is a new service by Uber that aims to provide an online marketplace for shipments in the long-haul truck \\
market. The platform brings together shippers and carriers and uses intelligent algorithms to reduce fuel costs and travel \\
times. As mentioned above, Uber Freight acquired the start-up Otto that focuses on the development of autonomous \\
trucks. This provides Uber Freight with access to trucking technologies and possible access to its own trucks [59]. \\
\hline Convoy \\
Much like Uber Freight, Convoy provides an online marketplace for trucking. Shippers can book trucks with mobile \\
devices and track their shipments in real time. By continuously adding further trucks (forwarders) to the system, Convoy \\
offers a comprehensive transportation network. In addition to that, the platform also provides further functions such as \\
payment and customer services [68]. \\
\hline Bringg \\
Bringg is a platform-based solution for the management of on-demand last mile deliveries. The basic idea is to provide \\
an "Uber-like" experience to businesses such as 3PLs and delivery companies. It allows dispatchers to assign tasks online, \\
track shipments and communicate with drivers through mobile devices. As of this writing, Bringg's service is available in \\
around 50 countries [69].
\end{tabular}

Table 5. Practical examples of vehicle manufacturer platforms.

\begin{tabular}{l} 
Vehicle Manufacturer Platforms \\
\hline Daimler Fleetboard \\
Fleetboard is a telematics based system provided by Daimler Benz. Vehicles are equipped with a mobile terminal for \\
communication and data gathering. Data are gathered centrally at a computer center and provided to the vehicle \\
operators. The aim of the system is to increase the economic efficiency of vehicle use through data mining. \\
The Fleetboard system has a wide range of complementary products and services including fleet management, \\
transportation management and reports of fleet data [70]. \\
Volkswagen (MAN) Rio \\
In 2016 Volkswagen (MAN) launched Rio, a cloud-based platform for global supply chains. The system works as an \\
information and application system and connects all parties involved in a transport, such as shippers, carriers and \\
recipients. The system gathers and analyzes different types of data such as navigational, vehicle and weather data. \\
This data can be used for real-time decisions and action recommendations. The aim is to increase transparency and \\
efficiency along the transport chain. The specific feature of Rio is that it can include data from other telematics \\
systems and is thus not limited to one provider only [71].
\end{tabular}

A second important application of platforms in the logistics service industry is data mining and data selling. Vehicle manufacturer platforms especially build on this principle. As the examples show, these platforms gather and evaluate data of vehicle use for provision to vehicle operators (in this case 3PLs). Vehicle operators then use these data for communication purposes such as transport management support and decision making. As the example of the Volkswagen (MAN) Rio platform illustrates, vehicle producers can use both knowledge and data to expand their platform services towards comprehensive supply chain management solutions.

(c) Value Chain Impact

As one-stop-shop solutions for arranging and managing logistics services, logistics marketplace platforms effect almost the entire 3PL value chain. Transports, as the main activity of 3PLs, are likely to be directly substituted by transports managed via logistics platforms, which have the advantage of being more transparent and customized. At the same time, the platform-based coordination of transports holds the potential to reduce the need for storage, which is substituted to a certain degree as well. In conclusion, classical transportation management and customer relationship management are especially likely to be replaced by the data-mining and transportation-planning algorithms of platforms, which erode the value of the IT solutions currently offered by 3PLs. Indeed, the impact of vehicle manufacturer platforms is more diverse. Activities related to physical goods movements are likely 
to be complemented by vehicle manufacturer platforms, as their functional focus lies in the efficient management of fleets and transports. However, at the same time, knowledge from these platforms is brought to the market in the form of new IT solutions, transportation management concepts and consulting services. As the functional range of the platform Rio shows, vehicle manufacturers are able to develop significant service capabilities in the area of order processing and administration. Therefore, vehicle manufacturer platforms bear the potential to replace the management-related and relationship-related activities of 3PLs.

\subsubsection{Buyer Power through Collaborative Consumption}

\section{(a) Practical Examples}

In the logistics service industry, two types of sharing platforms can currently be distinguished: cargo space sharing platforms and customer-to-customer (C2C) transport platforms. Cargo space sharing platforms are online marketplaces that provide the possibility of booking unused or excess transport or storage capacities on vehicles or in warehouses operated by logistics service providers. Customer-to-customer transport platforms are online marketplaces that allow private persons to offer unused space in vehicles for cargo transport. Practical examples of both are presented in Tables 6 and 7 .

\section{(b) Theoretical Reasoning}

As can be seen from the practical examples, sharing businesses in the logistics industry are mainly active in the field of transportation of smaller goods. Nevertheless, as companies such as Flexe show, initial efforts aim to expand the concept of the sharing economy to other logistics activities such as warehousing.

Two important aspects of the sharing economy have to be distinguished when looking at the logistics industry from a theoretical point of view. First, online sharing platforms allow for direct communication between buyers and providers of logistics services. This direct interaction enhances transparency and allows parties to publish and utilize extra capacities such as cargo space that would otherwise not have been communicated to the market. This mechanism constitutes a benefit for 3PLs, as available capacities can be utilized more efficiently. However, the more efficient use of cargo space may simultaneously lead to a decline in transport orders, as the same number of services can be performed with fewer physical resources.

Second, as the practical examples show, sharing platforms allow potential buyers of logistics services to offer their own private transport capacities to markets. This represents the classic working principle of the sharing economy, which enables consumers to become producing consumers or "prosumers." This development constitutes an example of backward integration, as service consumers take on the same activities as service producers (3PLs). Furthermore, the sharing principle allows customers to build up significant market power through network effects. As increasing numbers of private transporters lead to increasing service coverage, the utility of the platform for customers grows with the number of its users. Consequently, buyers can take over significant market shares by providing their own services concentrated on sharing platforms. A first indication of the increasing professional significance of $\mathrm{C} 2 \mathrm{C}$ transport sharing platforms can be seen in the business model of Deliv, which uses private drivers for $\mathrm{B} 2 \mathrm{C}$ home deliveries from stores. 
Table 6. Practical examples of cargo space sharing platforms.

\begin{tabular}{l} 
Cargo Space Sharing Platforms \\
\hline Cargomatic Less-than-Truck-Load (LTL) Service \\
Cargomatic is an app-based platform provider connecting shippers and carriers. Cargomatic offers a service that allows \\
parties to utilize excess cargo space in trucks. Shippers can post small shipments on the Cargomatic platform. Trucks \\
that are in the area and have spare capacity can view and accept these posted shipments via mobile devices. The service \\
is currently available within a range of 150 miles around the cities of Los Angeles, New York and San Francisco [2]. \\
\hline uShip Less-than-Truck-Load (LTL) Service \\
Like Cargomatic, uShip is an online marketplace for transports. The marketplace cooperates with professional truck \\
carriers and can be used by brokers, businesses and private persons. uShip provides the possibility of using excess \\
cargo space in trucks for small cargo parties (LTL). The service is available in several countries around the globe [72]. \\
\hline Flexe \\
Flexe is a warehousing marketplace for on-demand storage. Excess warehouse capacities can be offered and booked \\
via a cloud-based platform. Flexe also offers additional services such as tracking, billing and reporting, contract \\
management and insurance. The service is based in the US and currently covers more than 200 warehouses [73]. \\
\hline
\end{tabular}

Table 7. Practical examples of customer-to-customer transport platforms.

\begin{tabular}{l} 
Customer-to-Customer (C2C) Transport Platforms \\
\hline DropHub \\
DropHub is a crowd-shipping platform. The basic idea is to utilize excess transport capacity in car trunks or suitcases of \\
travelers for the transportation of goods. The aim is to provide mutual benefits by reducing travel costs through the fee \\
paid for transportation as well as by providing cheaper rates for direct shipments. Basically, this shipping model allows \\
parties to ship goods of all sizes on various routes (depending on the available capacity and trip leg) [74]. \\
\hline Deliv \\
Deliv is a start-up focusing on crowd-sourced last mile deliveries. Deliv uses private drivers with cars to pick up and \\
deliver shipments from retailers and small stores to consumers. This allows drivers to earn money for delivery and \\
enables retailers and stores to establish a home delivery system without their own infrastructure (through a partnership \\
with Deliv). Communication is offered via an online platform and mobile applications on smartphones [75]. \\
\hline Roadie \\
Roadie is an app-based peer-to-peer delivery network. Goods can be shipped by private persons in empty trunks or \\
spaces of cars or vans. The possible size of the consignment depends on the size of the respective vehicle. The service is \\
available in the US and provides all transport ranges from local to nationwide [76]. \\
\hline
\end{tabular}

\section{(c) Value Chain Impact}

First, it must be noted that cargo space sharing platforms enable 3PLs to optimize capacity utilization and thereby reduce empty runs of trucks and unused storage capacity. From this point of view, cargo space sharing platforms are complementary to existing 3PL activities and help to mitigate cost-intensive operational challenges. Nevertheless, cargo space sharing platforms simultaneously have the potential to substitute transport and storage services, as more efficiently using capacities may reduce the activities required. Moreover, the 3PL activities of transportation management, IT services and customer relationship management are likely to be substituted by coordinative functions and the interfaces of sharing platforms. The main impact of $\mathrm{C} 2 \mathrm{C}$ transport platforms on 3PL value chains lies in the partial substitution of local transportation. As private persons are new actors on the transport market, their transportation offers compete to a certain extent with similar services offered by 3PLs. Although substitution is limited physically by possible size and weight of shipped goods, 3PLs may lose significant market shares in the segment of small regional consignments if $\mathrm{C} 2 \mathrm{C}$ transport platforms grow significantly. As with the other platforms presented above, logistics management services and customer relationship management services are entirely substituted by the digital functions of $\mathrm{C} 2 \mathrm{C}$ transport platforms. 


\subsubsection{Threat of Substitutes through the Long Tail Effect}

\section{(a) Practical Examples}

Examples of the long tail effect in logistics can be classified into two larger categories: substitutes for logistics, which are new technologies that replace the need for logistics; and logistics niche services, which have the potential to replace today's standard logistics services. Practical examples of both are presented in Tables 8 and 9.

\section{(b) Theoretical Reasoning}

The long tail effect may lead to direct and indirect substitution of logistics services. Indirect substitution originates from new non-logistics-related technologies that have the potential to make logistics superfluous. For example, 3D printing (alternatively called additive manufacturing) hardly shares commonalities with logistics but substitutes shipments by printing required goods on demand and directly on site. Further technical evolution of 3D printing holds the potential to make an increasing number of products printable and thus reduces the need for conventional logistics [77]. The growing range of printable products corresponds to the long tail effect. From this point of view, the long tail effect is closely related to the theory of the attacker's advantage, as it constitutes a technological disruption. In the example of parcel lockers, the long tail effect becomes apparent in that customers can choose from an increasing number of pick-up stations, which can be considered as an individualized niche service. Representing a new logistics concept beyond the scope of classical deliveries, parcel lockers can also be classified as an indirect substitute for standard logistics services.

As for direct substitution, current standard solutions are replaced by new logistics service niches that fulfill specialized requirements from customers better than the standard services currently on offer. On one hand, such service replacements are realized through platform-based marketplaces and sharing businesses, as described above. Platforms allow customers to find solutions that perfectly match their individual requirements, especially regarding place and time of transport or delivery. From this point of view, the long tail effect is closely linked to network effects, as an increasing number of service suppliers using a platform also leads to a growing number of services supplied. This in turn enhances the likelihood of finding individually fitted solutions. On the other hand, the long tail effect also allows parties to find logistics services that fulfill completely new requirements not offered by standard providers, such as emissions-free transportation in the case of the start-up Fairtransport. Such services can easily be found and acquired online, which significantly reduces search costs for customers. While Fairtransport offers only maritime transportation, the probability of expanding similar business models to land-based transport is deemed to be high. In addition to that, with regard to the growing importance of environmental sustainability, the demand for such clean transport solutions is likely to rise.

Table 8. Practical examples of substitutes for logistics services.

\begin{tabular}{l} 
Substitutes for Logistics Services \\
\hline 3D Printing (Case of General Electric) \\
3D printing is a technology that enables the production of three-dimensional objects from data files such as construction \\
plans (CAD) or three-dimensional scans [78]. A recent example of the increasing use of 3D printing is the company \\
General Electric, which has started to produce new fuel nozzles for aircraft turbines using 3D printing [79]. As 3D printing \\
requires only data in the form of plans, no supply parts have to be shipped to India, where the nozzles are produced. \\
Amazon Locker \\
With the aim of gaining independence from logistics service providers, the e-commerce company Amazon is launching a \\
parcel locker service. Lockers for parcels from Amazon shipments are placed at convenient locations such as gas stations. \\
Customers can order the dropping of parcels at a locker of their choice. Instead of waiting for delivery, they can pick \\
parcels up at any time [80].
\end{tabular}


Table 9. Practical examples of logistics niche services.

\begin{tabular}{l} 
Logistics Niche Services \\
\hline Fairtransport \\
Fairtransport is a shipping company based in the Netherlands. The aim is to provide completely emissions-free \\
worldwide transportation of organic goods as an environmentally friendly alternative to conventional shipping by large \\
motor vessels. So far, the company operates two smaller ships and aims to expand its fleet with larger units [81]. \\
\hline Platform Marketplaces for Logistics Services \\
As outlined above, platform-based logistics marketplaces and sharing businesses offer the possibility of arranging almost \\
any individual service required (such as transportation on special legs). This most notably includes niche services barely \\
offered by 3PLs, such as flexible home deliveries. These points are consistent with the characteristic long-tail feature of \\
"selling less of more".
\end{tabular}

\section{(c) Value Chain Impact}

Technologies such as 3D printing hold the potential to render logistics services entirely superfluous. Consequently, all the value chain steps and activities of 3PL could potentially be substituted by these technologies.

Niche logistics services constitute alternatives to standard services and thus could potentially replace transportation-related activities. However, the substitution remains at present on a partial level, as the service examples listed are focusing on specific niches. This partial substitution of 3PL activities is also true for management services and customer relationship management, as niches need their own appropriate solutions and address their specific target customers. The effects of platform-based businesses on the 3PL value chain have already been discussed.

\subsubsection{Rivalry among Competitors through the Industrialization of Services}

Rivalry among competitors in connection with the industrialization of services stands at the center of the framework and is the force resulting from the other four forces and theories. Therefore, the analysis of this force deviates from the suggested analysis procedure and focuses on a general theory-based explanation.

As von der Gracht and Darkow [82] outline, increasing competition in spite of significant industry growth remains an important uncertainty factor for the logistics service industry. With respect to Porter's descriptions, the rivalry among competitors in the logistics service industry is fueled by the general characteristics of services, which include the inseparability of consumption and production as well as perishability $[83,84]$. This not only implies that services cannot be stored but also that service providers have to provide capacities for implementing their services. In the logistics service industry, providing service capacities requires capital-intensive physical assets such as vehicle fleets and warehouses, which render unused capacities expensive. Accordingly, actors in the logistics service industry (3PL) need to optimize their capacity utilization. When looking at service industrialization, two components of 3PL services-the physical and the non-physical components-have to be considered separately.

As already outlined, the most common physical services of 3PL are transportation (long-haul and short-haul) and warehousing. If shipments have no specialized requirements, such as general cargo or parcels, the activities of transportation and warehousing can basically be carried out by any provider. Consequently, transportation and warehousing can be considered highly standardized physical components of logistics services, a standardization that renders providers easily interchangeable. This statement finds practical support in the increasing use of standardized packages and vehicles, such as standard containers (i.e., TEUs), standardized pallet sizes (i.e., Euro-pallets) and standardized truck sizes. This standardization enables especially the spreading of platform-based logistics marketplaces, where shippers can choose among offers from many providers (or prosumers in the case of a sharing platform) for the same service. Thus, a core feature of platforms such as Freightos [85] is the direct comparison of shipment quotes from different LSPs or carriers. Regarding Porter's description of 
competitor rivalry, this can be considered an expression of a price war. In addition, the high degree of standardization makes transportation and warehousing accessible for new technologies such as automation and autonomous vehicles, an aspect that additionally increases competition.

Furthermore, 3PLs offer several non-physical services such as logistics management, order processing and additional IT services. As the practical examples in the analysis show, the majority of such services can be carried out or are supported by digital technologies and digital services. As Leimeister [84] explains, digital services are increasingly automated and modularized. This allows parties to build up their own digital services by simply combining standardized service modules following a construction-kit logic with different interfaces. This not only constitutes the industrialization of digital services but also enables all providers to easily develop and establish such services, which additionally increases rivalry. This conclusion is supported by the practical examples stated in the analysis. Logistics marketplace platforms (and sharing platforms) in particular offer very similar IT based services such as ordering via mobile devices or real-time tracking and tracing of shipments on digital maps. Autonomous vehicles and drones or robots for local transportation can be accessed through such digital services as well.

Finally, Figure 5 summarizes the value chain impact of each stated practical example. This summary serves as basis for the following discussion.

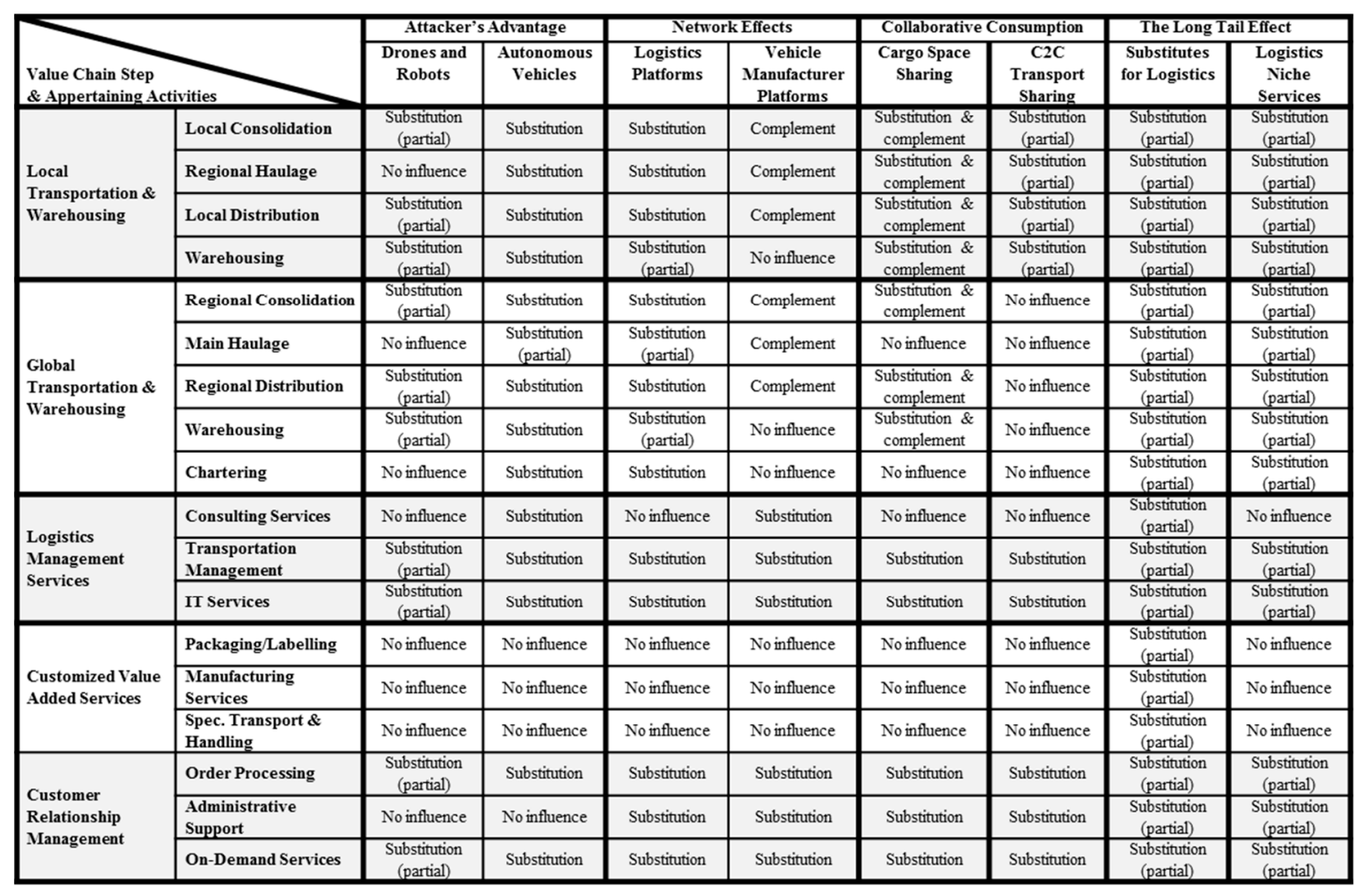

Figure 5. Impact overview of the digitalization examples on the 3PL value chain. As can be seen, local transportation and warehousing are especially likely to be substituted. The only value chain step hardly affected at all is customized value-added services.

\section{Discussion}

As the industry analysis revealed, digitalization is building a new competitive arena as it influences the business models of 3PL from all "sides" of the identified force-theory relations. Regarding the impact on the value chain (see Figure 5), the analysis showed that activities in all steps of the 3PL value chain are likely to be affected. The only exception is customized value-added services, which 
encompass comparatively specialized activities. In sum, three major threats arising for 3PLs from digital disruptions can be extracted:

- $\quad 3 P L s$ focusing on standardized services such as transportation and warehousing are likely to lose significant market share to new transport technologies and customized service solutions.

- Management-related 3PL services are increasingly offered by new external providers such as online logistics platforms, which renders 3PLs "simple" forwarders.

- There are simultaneous threats of forward and backward integration by platform providers (suppliers) such as Uber Freight and large customers of logistics services such as Amazon.

We now discuss the threats in more detail. This description of threats should give answers to the main RQ of this paper.

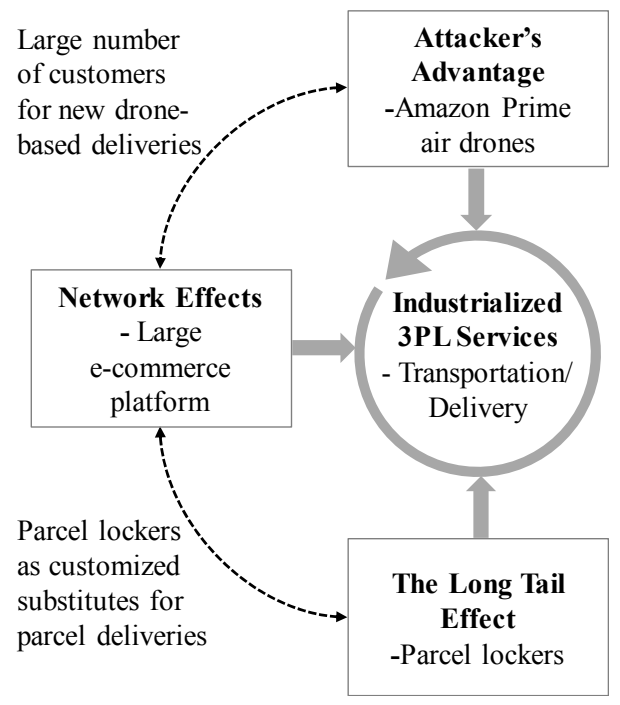

(a)

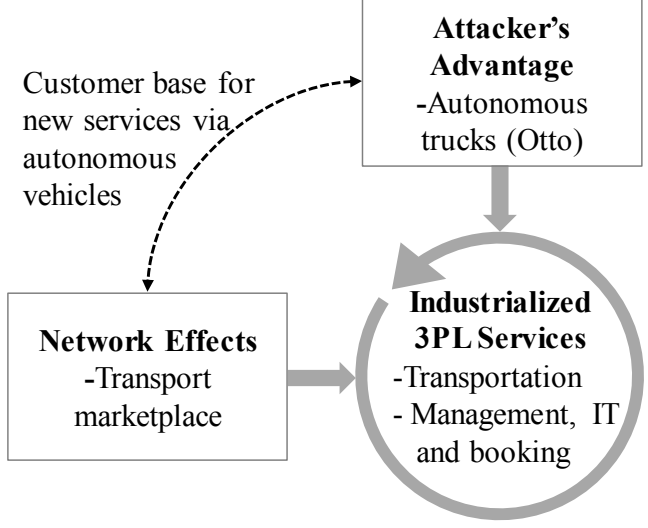

(b)

Figure 6. Simultaneous forward and backward integration by Amazon (a) and Uber Freight (b) using the attacker's advantage and network effects (and the long tail effect). This especially affects standard 3PLs that provide highly industrialized services.

\subsection{Loss of Market Share for Standard Service Providers}

Standard regional providers primarily focus on transportation and warehousing on a local scale and may additionally provide related management services. However, as the value chain impact overview reveals, activities from the value chain step "local transportation and warehousing" are especially likely to be substituted by most of the examples cited for digital technologies and services. This vulnerability originates from the fact that local 3PL services mainly consist of short-range transports of comparatively small cargo pieces including CEP. As the practical examples show, the same market is served by most logistics platform marketplaces and transport sharing platforms. In addition, new technologies such as drones and substitutes for logistics (parcel lockers) aim to enter this market segment as well. The advantage of these new offers over 3PL services is the higher degree of potential service customization in connection with greater service transparency through mobile devices and real-time tracing functions. These findings mirror the results of a study conducted by McKinsey \& Company [9] that states that, especially in urban centers, the demand for individualized logistics services is increasing and is being met by new technologies and crowd-sourced transportation. In view of these points, it can be concluded that standard local providers are simultaneously affected by all forces and thus are likely to lose significant market share to new digital-based services and technologies.

The same arguments basically also hold true for standard international providers. The impact of digital technologies on international transportation and warehousing consists mainly of (partial) 
activity substitution. The overall effect is considered to be weaker than for local transportation and warehousing, as distances, transport vehicles and amounts shipped are significantly larger. These points physically limit the possible alternatives. Nevertheless, as outlined above, new technologies such as automated vehicles and 3D printing, especially, hold the potential to reshape global goods transportation and thus are also likely to significantly affect the business of standard international providers [86]. As the success of companies such as Amazon (which is one of the largest booksellers without selling physical books) and iTunes (which is one of the largest music sellers without selling physical CDs) shows, the replacement of physical goods with digital substitutes holds the potential to change entire global industries_-and this will hit the business models of 3PLs.

\subsection{Loss of Management Services to External Service Providers}

The second major threat identified affects the business model of international service specialists as well as the business model of standard providers (regional and international). As can be seen from the value chain impact overview, activities from the 3PL value chain steps "logistics management services" and "customer relationship management" are likely to be substituted by new service offers and technologies. As explained in the practical examples, this holds particularly true for platform-based logistics marketplaces and sharing platforms that enable customers to arrange and manage logistics services independently - that is, according to their individual preferences and without any further support by 3PLs. In addition, new technologies such as drones are equipped with their own order processing and customer interface services such as APIs (application programming interfaces) and mobile applications. These new services threaten especially the business model of international service specialists that provide to a large degree non-physical services such as logistics management and customer relationship management. If these services are taken over by external providers such as platform operators, the activity range of service specialists is likely to be reduced to mainly physical components such as transportation and warehousing. The same scenario also applies to standard providers (regional and international), which are likely to lose their already small proportion of management services to external providers. These developments are strengthened by network effects that increase the power of platform suppliers and render 3PLs dependent on such platforms. In essence, the characteristic role of 3PLs as providers of extensive logistics services is likely to be eroded and changed into the role of the "simple" carrier or forwarder that can be booked via a platform. This assumption is supported by drawing analogies to the travel industry, where new online travel agencies are gaining increasing importance and are fueling competition [87]. Online booking portals such as HRS (more information at http:/ /www.hrs.com) and Booking.com (more information at https: / / www.booking.com) allow especially directly comparison of booking offers from various providers, disrupting the traditional models of hotel and travel booking.

\subsection{Forward and Backward Integration by Platform Providers and E-Commerce Companies}

The third threat results from the dynamic interdependencies between the force-model combinations and is considered to be the most significant threat. As the industry analysis shows, platform providers and e-commerce companies especially, which until now have been customers, suppliers, or otherwise partners of 3PL, have entered the logistics service industry by providing their own digital-based logistics solutions. In doing so, these companies have put pressure on 3PL by making simultaneous use of several disruptive mechanisms, as the examples of Uber and Amazon show.

As described above, Amazon has entered the logistics industry by introducing its own parcel lockers and drone-based delivery services. Regarding the analysis framework, Amazon has put pressure on 3PL by profiting from three competitive forces at the same time, as shown in Figure 6a. Due to its size Amazon profits as a platform-based marketplace from network effects and has significant market power. The large customer base enables Amazon to introduce new service technologies and concepts such as drones and parcel lockers. In doing so, Amazon can build on existing logistics knowledge and technological knowledge from its current booking services, as well as on customer 
data. Using a combination of these factors, Amazon holds the potential to turn into a competitor for 3PL by providing a one-stop-shop solution for e-commerce and delivery logistics. This especially affects standard service providers that are active in the field of e-commerce parcel deliveries [88].

Uber Freight aims to enter the logistics services industry by using a mechanism similar to Amazon's. Uber Freight is currently establishing a platform marketplace for long-haul trucking services. This allows Uber Freight to build up a large customer base by profiting from network effects and turns Uber into a service supplier for 3PL. The acquisition of Otto enables Uber Freight to additionally develop its own fleet of autonomous trucks that can be booked and managed digitally through the platform. This combination allows Uber Freight to become a full logistics service provider and drive current 3PLs out of the market, as automation allows for significant reduction of costs. This especially affects standard providers that are active in the field of truck-based transportation. The mechanism is further described in Figure $6 \mathrm{~b}$.

\section{Conclusions and Outlook}

\subsection{Opportunities for 3PLs in the Digital Age}

With their current business models, 3PLs face significant hardship from digitalization. The competitive mechanisms in the industry are changing rapidly and opening the arena for completely new actors. Consequently, 3PLs have to react to these developments in order to defend their position as core providers for logistics solutions.

The disruption mechanisms identified in this paper serve as a basis for the elaboration of digital opportunities for 3PLs. Making use of the same underlying working mechanisms constitutes a comprehensive foundation for counteracting the identified threats directly. As indicated in Figure 7, the 3PL opportunity for elaboration follows a logic counter to the industry analysis, as it starts from the framework center and subsequently describes countermeasures for each force and theory. From this angle, the industrialization and standardization of logistics services can be seen as the root of the problem. Nevertheless, as consultancy studies [9] and practitioner studies [8] point out, the demand for tailored delivery and customized logistics services is on the rise. Consequently, standard providers especially, which have the most endangered business model, need to look for opportunities to differentiate their services and reduce costs. This can be achieved by making use of the other four force-model combinations.

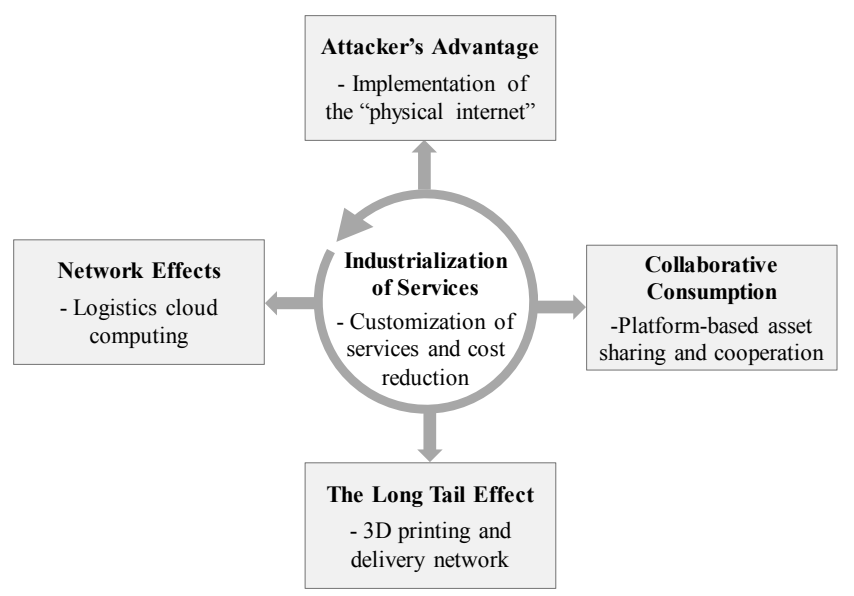

Figure 7. Elaboration of opportunities for 3PL arising from digital disruptions. The logic counter to the industry analysis is indicated by arrows pointing from the inside out. 


\subsubsection{Attacker's Advantage: Physical Internet}

As the industry analysis has shown, traditional 3PLs are under attack by new transportation technologies such as autonomous vehicles, drones and robots. In order to counteract this threat, 3PLs not only need to adapt to these technologies but also foster the development of their own technologies to stay in the lead. One technological development currently being discussed as a future transport and logistics solution is the "physical internet" [89]. The basic idea of the physical internet is to apply the logic of data transmission over the internet to physical transportation of goods. On the internet, data are not transferred individually but are processed in the form of information packages that are routed to their destination. The digital internet is thus based on protocols that allow data to be handled by different networks and systems. In a similar way, the physical internet initiative aims to develop worldwide standardized and modularized containers for the translocation of physical objects. The modular containers are accordingly composed (and decomposed) from several smaller subunits and can be easily handled by a variety of systems [89]. The container subunits are connected to each other via the internet using connective technologies such as GPS sensors and RFID chips [89]. The result is a hyper-connected global logistics system that enables seamless asset sharing and flow consolidation. By co-developing and adapting the physical internet, 3PLs have the opportunity to shift from classical transportation modes to a new global concept that is less threatened by and additionally can be combined with, new transport devices.

\subsubsection{Collaborative Consumption: Platform-Based Asset Sharing and Cooperation}

While the sharing economy threatens standard providers especially, it offers significant opportunities for 3PLs at the same time. As pointed out in the industry analysis, cargo space sharing and warehouse sharing allow for a more efficient allocation of existing capacities. The efficient use of existing capital-intensive capacities is vital for the profitability of logistics companies. As the practical examples demonstrate, cargo space sharing services are currently mainly provided by external platform companies and start-ups. Thus, the opportunity arising from the sharing economy for 3PLs is the possibility for them to set up their own platform-based sharing solutions, either through cooperation with technology partners or through the development of their own platforms [10]. The concept of sharing can be further expanded into the sharing of logistics assets and infrastructures among several 3PLs, which further increases capacity utilization and thus reduces costs [8]. In addition, online sharing platforms can be used for a more general horizontal cooperation between 3PLs, such as sharing of provided services. As Cruijssen et al. [90] point out, horizontal cooperation between LSPs increases-among other things-the productivity of core activities and allows LSPs to specialize while simultaneously broadening the service scope. Thus, this effect allows 3PLs to further customize services-which matches the increasing demand for tailored logistics-without larger financial investment. Finally, platform-based horizontal cooperation allows 3PLs to bundle market power and thereby counteract the growing buyer power emerging from peer-to-peer sharing.

\subsubsection{Network Effects: Cloud Logistics and Logistics Malls}

As regards network effects, 3PLs are confronted with logistics marketplace platforms as well as with new platform-based supply chain solutions provided by vehicle manufacturers. To counteract this threat, 3PLs have the opportunity to adopt the technology of cloud computing. Cloud computing allows them to provide IT services via the internet. In so doing, they can outsource activities linked to software and hardware management without losing focus on their own competencies. Different applications and IT systems interact on the cloud and can be accessed via web browsers (or apps) without installing any software components locally [91]. In the logistics service industry, the first cloud computing solutions-including the Logistics Mall [92] developed by the Fraunhofer Institute of Material Flow and Logistics (Germany) - are being realized. The concept of the Logistics Mall is to combine small, individual logistics IT services from different service providers into superior, 
customized services that are used by logisticians or other customers [91]. In addition to being a marketplace for logistics IT services and processes, the mall has the future aim of integrating the business-process management of physical services such as transportation or warehousing [91]. For 3PL, this would potentially allow parties to gain access to logistics cloud platforms by developing compatible service modules. The combination of services from various providers enables 3PL to be integrated into multi-provider customized solutions. Finally, the easy accessibility of services via the cloud, as well as the combination of services, allows 3PL to profit from both direct and indirect network effects.

\subsubsection{The Long Tail Effect: 3D Printers and Delivery Networks}

As an increasing number of products can simply be printed out, 3D printing holds the potential to significantly change global goods flows, replacing traditional logistics services. As pointed out by the research department of DHL [11], 3D printing in consequence has important implications for future supply chains. With regard to 3PLs, although it disrupts logistics, 3D printing offers valuable opportunities to expand business models and directly counter this threat. For example, 3PLs may build up dense networks of shared 3D printers located in warehouses and distribution centers. These printers can be used for the customized on-demand production of spare parts or individualized parts for different manufacturers and private customers. The parts can be delivered immediately after printing, which significantly reduces lead times and inventory costs [11]. Another concept, which helps to further reduce lead times, is to fit 3D printers on trucks. This allows service providers to print and produce goods on the way to their destination [11]. The combination of 3D printing with transportation and warehousing is especially suitable for standard providers, which can easily complement their existing infrastructure with 3D printers. This step further allows standard providers to customize their services and benefit from economies of scale, as the printers can be used for projects from different clients.

Finally, the digital opportunities outlined enable 3PLs to respond strategically to two significant demand trends identified in a recent study on the status of logistics outsourcing [93]. First, there has been a consistently high demand from shippers for execution- and transaction-based digital 3PL services. This includes IT capabilities such as transportation management (planning), EDI services and increased transparency in logistics (orders, shipments, inventory, etc.) as well as web portals for booking and tracking. However, up to now, there is still a significant "IT gap" between the IT services provided by 3PLs and the IT services demanded by shippers. In order to stay in the lead, 3PLs have to close this gap. Second, shippers are also demanding increasing involvement by 3PLs in the transformation of their supply chains. In view of the logistics service provider clustering presented in Section 3.1, this is tantamount to an increased demand for 4PL services. Consequently, 3PLs need to expand their business models by developing solutions related to supply chain management. With regard to the opportunities outlined, this can be achieved by making use of platform-based services such as the Logistics Mall.

All in all, only the future can tell which path is the right one to follow. As this paper shows, digitalization bears both significant threats and large opportunities for 3PL. Nevertheless, digital inactivity would definitely be the worst choice for 3PLs. The goal of 3PLs should be to become digital game changers themselves by taking proactive measures.

\subsection{Limitations of This Study}

The first limitation concerns the conceptual nature of this paper. The main aim is to provide new, industry-wide perspectives on the analysis of digital disruptions in logistics. Therefore, rather than provide in-depth results, this paper serves as a starting point for further research on different aspects of digital disruptions.

Second, regarding the analysis of practical examples, it must be noted that we extrapolated current developments into future scenarios. As experiences from other industries show, digitalization brings along rapid and unexpected changes. Consequently, further developments of the business models 
and technologies presented, as well as their final impacts on 3PL, have to be awaited and cannot be fully predicted.

\subsection{Implications for Future Research}

Taking into account the limitations outlined above, we recommend the following next steps for research on digital disruptions in logistics:

- First, there is need for further academic research on the acceptance and practical implementation of new technologies such as drones and robots in the logistics industry. This can be achieved by applying established concepts such as the technology acceptance model [94] or the Delphi method to future technological scenarios [82].

- The second research recommendation addresses the impact of platform business models on the logistics industry. While this paper takes a qualitative view of online logistics marketplaces and logistics sharing platforms, there is clear need for quantitative assessments of the impact of such platform businesses on the logistics industry and its markets.

- The third research recommendation would be to consider the options for 3PLs arising from digitalization. On one hand, each of the options outlined in this paper needs to be further elaborated and evaluated in depth. This can be achieved by making use of established business model innovation concepts such as the Business Model Canvas [55] or the Magic Triangle [95]. On the other hand, further research in this direction offers the potential to develop entirely new business models for logistics services.

Conflicts of Interest: The authors declare no conflict of interest.

\section{References}

1. Bolumole, A.Y. The Supply Chain Role of Third-Party Logistics Providers. Int. J. Logist. Manag. 2001, 12, 87-102. [CrossRef]

2. Cargomatic Inc. A Revolution in Local Trucking. Available online: https://www.cargomatic.com (accessed on 10 January 2017).

3. Uber Freight. Tap a Button, Book a Load. Available online: https://freight.uber.com (accessed on 20 July 2017).

4. Amazon Logistics. Deliver with Amazon. Available online: https://logistics.amazon.com (accessed on 10 January 2017).

5. Oliver Wyman. Start-Ups Rollen Logistikbranche Auf. Available online: http://www.oliverwyman.de/ who-we-are/press-releases/2017/Start-ups-rollen-Logistikbrancheauf.html (accessed on 9 January 2017).

6. World Bank. Connecting to Compete. Trade Logistics in the Global Economy 2016. Available online: https://wb-lpi-media.s3.amazonaws.com/LPI_Report_2016.pdf (accessed on 20 August 2017).

7. Osterwalder, A. The Business Model Ontology A Proposition in a Design Science Approach. Ph.D. Thesis, University of Lausanne, Lausanne, Switzerland, 2004.

8. Deutsche Post DHL Group. Logistics Trend Radar. Delivering Insight Today. Creating Value Tomorrow! version 2016; DHL Customer Solutions \& Innovation: Troisdorf, Germany, 2016.

9. McKinsey \& Company. Delivering Change: The Transformation of Commercial Transport by 2025; McKinsey \& Company: New York, NY, USA, 2016.

10. Deloitte. The rise of the sharing economy. In Impact on the Transportation Space; Consultancy Study; Deloitte: New York, NY, USA, 2016.

11. Deutsche Post DHL Group. 3D Printing and the Future of Supply Chains. In A DHL Perspective on the State of 3D Printing and Implications for Logistics; DHL Customer Solutions \& Innovation: Troisdorf, Germany, 2016.

12. Harris, I.; Wang, Y.; Wang, H. ICT in multimodal transport and technological trends: Unleashing potential for the future. Int. J. Prod. Econ. 2015, 159, 88-103. [CrossRef]

13. Delfmann, W.; Albers, S.; Gehring, M. The impact of electronic commerce on logistics service providers. Int. J. Phys. Distrib. Logist. Manag. 2002, 32, 203-222. [CrossRef] 
14. Kim, C.; Yang, K.H.; Kim, J. A strategy for third-party logistics systems: A case analysis using the blue ocean strategy. Omega 2008, 36, 522-534. [CrossRef]

15. Varella, L.; Buss Gonçalves, M. Information Technology as the Main Competence in the Design of the Strategic Planning of Logistics Platforms. J. Technol. Manag. Innov. 2013, 8, 160-172. [CrossRef]

16. Cheng, M.C.; Wang, J.J. An integrative approach in measuring hub-port supply chain performance: Potential contributions of a logistics and transport data exchange platform. Case Stud. Transp. Policy 2016, 4, 150-160. [CrossRef]

17. Nguyen, H.O. Critical factors in e-business adoption: Evidence from Australian transport and logistics companies. Int. J. Prod. Econ. 2013, 146, 300-312. [CrossRef]

18. Porter, M.E. How Competitive Forces shape Strategy. Harv. Bus. Rev. 1979, 57, 137-145.

19. Elliot, C. Industrial Economics. Available online: http://www.studyingeconomics.ac.uk/module-options/ industrial-economics / (accessed on 16 August 2016).

20. Schmalensee, R.L. Industrial Economics: An Overview; Working Paper; Sloan School of Management, Massachusetts Institute of Technology: Cambridge, MA, USA, 1988.

21. Porter, M.E. The Contributions of Industrial Organization to Strategic Management. Acad. Manag. Rev. 1981, 6, 609-620.

22. Porter, M.E. Five Competitive Forces That Shape Strategy. In HBR's 10 Must Reads on Strategy; Porter, M.E., Kim, W.C., Mauborgne, R., Eds.; Harvard Business Review Press: Boston, MA, USA, 2011; pp. $23-41$.

23. Itälä, T. Digital Businesses and Platforms. In IT Leadership in Transition. The Impact of Digitalization on Finnish Organizations; Collin, J., Hiekkannen, K., Korhonen, J.J., Halen, M., Itälä, T., Helenius, M., Eds.; Aalto University Department of Computer Science: Espoo, Finland, 2015; pp. 50-57. ISBN 978-952-60-6243-3.

24. Li, J.; Merenda, M.; Venkatachalam, A.R. Business Process Digitalization and New Product Development: An Empirical Study of Small and Medium-Sized Manufacturers. Int. J. E-Bus. Res. 2009, 5, 49-64. [CrossRef]

25. Westermann, G.; Bonnet, D. Revamping Your Business through Digital Transformation. MIT Sloan Manag. Rev. 2015, 56, 10-13.

26. Brynjolfsson, E.; Hu, Y.; Smith, M.D. Consumer Surplus in the Digital Economy: Estimating the Value of Increased Product Variety at Online Booksellers. Manag. Sci. 2003, 49, 1580-1596. [CrossRef]

27. Barnes, S.J.; Matsson, J. Understanding current and future issues in collaborative consumption: A four-stage Delphi study. Technol. Forecast. Soc. Chang. 2016, 104, 200-211. [CrossRef]

28. Lehdonvirta, V. A history of the digitalization of consumer culture: From Amazon through Pirate Bay to FarmVille. In Digital Virtual Consumption; Denegri-Knott, J., Molesworth, M., Eds.; Routledge: New York, NY, USA, 2012; pp. 11-28.

29. Mäenpää, R.; Korhonen, J.J. Digitalization in Retail: The Impact on Competition. In IT Leadership in Transition. The Impact of Digitalization on Finnish Organizations; Collin, J., Hiekkannen, K., Korhonen, J.J., Halen, M., Itälä, T., Helenius, M., Eds.; Aalto University Department of Computer Science: Espoo, Finland, 2015; pp. 89-102. ISBN 978-952-60-6243-3.

30. Karagiannopoulos, G.D.; Georgopoulos, N.; Nikolopoulos, K. Fathoming Porter's five forces model in the internet era. Info 2005, 7, 66-76. [CrossRef]

31. Foster, R. The Attacker's Advantage; Summit Book: New York, NY, USA, 1986.

32. Christensen, C.M.; Rosenbloom, R.S. Explaining the attacker's advantage: Technological paradigms, organizational dynamics and the value network. Res. Policy 1995, 24, 233-257. [CrossRef]

33. Modis, T. Genetic Re-Engineering of Corporations. Technol. Forecast. Soc. Chang. 1997, 56, 107-118. [CrossRef]

34. Christensen, C.M.; Bower, J.L. Customer Power, Strategic Investment and the Failure of Leading Firms. Strateg. Manag. J. 1996, 17, 197-218. [CrossRef]

35. Cennamo, C.; Santalo, J. Platform Competition: Strategic Trade-Offs in Platform Markets. Strateg. Manag. J. 2013, 34, 1331-1350. [CrossRef]

36. Eisenmann, T.; Parker, G.; van Alstyne, M.W. Strategies for Two-Sided Markets. Harv. Bus. Rev. 2006, 84, 92-101.

37. Katz, M.L.; Shapiro, C. Systems Competition and Network Effects. J. Econ. Perspect. 1994, 8, 93-115. [CrossRef]

38. Bardhi, F.; Eckhard, G.M. Access-Based Consumption: The Case of Car Sharing. J. Consum. Res. 2012, 39, 881-898. [CrossRef] 
39. Marchi, A.; Parekh, E.-J. How the Sharing Economy Can Make Its Case. Available online: http:/ / www.mckinsey.com/business-functions/strategy-and-corporate-finance/ourinsights/howthe-sharing-economy-can-make-its-case (accessed on 12 August 2016).

40. Ritzer, G.; Dean, P.; Jurgenson, N. The Coming Age of the Prosumer. Am. Behav. Sci. 2012, 56, 379-398. [CrossRef]

41. Anderson, C. The Long Tail: Why the Future of Business Is Selling Less of More; Hyperion: New York, NY, USA, 2006.

42. Elberse, A. Should You Invest in the Long Tail? Harv. Bus. Rev. 2008, 86, 88-96.

43. Brynjolfsson, E.; Hu, Y.; Simester, D. Goodbye Pareto Principle, Hello Long Tail: The Effect of Search Costs on the Concentration of Product Sales. Manag. Sci. 2011, 57, 1373-1386. [CrossRef]

44. Brynjolfsson, E.; Hu, Y.; Smith, M.D. From Niches to Riches: Anatomy of the Long Tail. MIT Sloan Manag. Rev. 2006, 47, 67-71. [CrossRef]

45. Miles, I. Services in the New Industrial Economy. Futures 1993, 25, 653-672. [CrossRef]

46. Schroth, C. The internet of services: Global industrialization of information intensive services. In Proceedings of the IEEE 2nd International Conference on Digital Information Management, Lyon, France, 28-31 October 2007.

47. Karmakar, U. Will You Survive The Services Revolution? Harv. Bus. Rev. 2004, 82, 100-107.

48. Hofmann, E.; Lampe, K. Financial statement analysis of logistics service providers: Ways of enhancing performance. Int. J. Phys. Distrib. Logist. Manag. 2013, 43, 321-342. [CrossRef]

49. Stefansson, G. Collaborative logistics management and the role of third-party service providers. Int. J. Phys. Distrib. Logist. Manag. 2006, 36, 76-92. [CrossRef]

50. Marasco, A. Third-party logistics: A literature review. Int. J. Prod. Econ. 2008, 113, 127-147. [CrossRef]

51. Lieb, R.C. The Use of Third-Party Logistics Service by Large American Manufacturers. J. Bus. Logist. 1992, 13, 29-42.

52. Berglund, M.; van Laarhoven, P.; Sharman, G.; Wandel, S. Third-Party Logistics: Is There a Future? Int. J. Logist. Manag. 1999, 10, 59-70. [CrossRef]

53. Murphy, P.R.; Poist, R.F. Third-party logistics usage: An assessment of propositions based on previous research. Transp. J. 1998, 37, 26-35.

54. Bagchi, P.K.; Virum, H. European Logistics Alliances: A Management Model. Int. J. Logist. Manag. 1996, 7, 93-108. [CrossRef]

55. Osterwalder, A.; Pigneur, Y. Business Model Generation: A Handbook for Visionaries, Game Changers and Challengers; John Wiley \& Sons: Hoboken, NJ, USA, 2010; ISBN 9780470876411.

56. Alfredsson, M.; Hertz, S. Strategic development of third party logistics providers. Ind. Mark. Manag. 2003, 32, 139-149. [CrossRef]

57. Prockl, G.; Pflaum, A.; Kotzab, H. 3PL factories or lernstatts? Value-creation models for 3PL service providers. Int. J. Phys. Distrib. Logist. Manag. 2012, 42, 544-561. [CrossRef]

58. Lemoine, W.; Dagnæs, L. Globalisation strategies and business organisation of a network of logistics service providers. Int. J. Phys. Distrib. Logist. Manag. 2003, 33, 209-228. [CrossRef]

59. Uber to Move Freight, Target Trucking for the Long Haul. Available online: http://www.reuters.com/ article/us-uber-truckingidUSKCN11Y0DI (accessed on 5 October 2016).

60. Autonom Durch Nevada. Freightliner Inspiration Truck. Available online: https:/ /www.daimler.com/ innovation/autonomes-fahren/freightliner-inspirationtruck.html (accessed on 10 October 2016).

61. The ReVolt. A New Inspirational Ship Concept. Available online: https://www.dnvgl.com/technologyinnovation/revolt/ (accessed on 5 October 2016).

62. Amazon Prime Air. Available online: https:/ / www.amazon.com/Amazon-Prime-Air /b? node=8037720011 (accessed on 29 July 2017).

63. Alphabet's Project Wing Delivery Drones to Be Tested in U.S. Available online: https:/ / www.bloomberg. com/politics/articles/2016-08-02/google-sproject-wing-delivery-drones-to-betested-at-u-s-site (accessed on 15 October 2016).

64. Post Testet Selbstfahrende Lieferroboter. Available online: https://www.post.ch/de/ueber-uns/unternehmen/ medien/medienmitteilungen/2016/posttestet-selbstfahrende-lieferroboter (accessed on 16 October 2016).

65. Fetch Robotics. Available online: https://www.fetchrobotics.com (accessed on 1 October 2017).

66. Auto Store. Available online: https:/ / autostoresystem.com (accessed on 1 October 2017). 
67. DriveNow Carsharing in Deutschland. Available online: https://www.drive-now.com/de/de (accessed on 29 July 2017).

68. Convoy. What Can Technology Do for Trucking? Available online: https://convoy.com (accessed on 29 July 2017).

69. Bringg. Customer-Centric Logistics for the Enterprise Market. Available online: https://www.bringg.com (accessed on 15 July 2017).

70. FleetBoard. Available online: https:/ /www.fleetboard.de/de/ (accessed on 1 July 2017).

71. Rio Sagt Hallo. Available online: https:/ / rio.cloud/de/ (accessed on 29 July 2017).

72. Uship. Available online: https://www.uship.com (accessed on 18 January 2017).

73. Flexe. The First, Largest Warehouse Services Marketplace. Available online: https://www.flexe.com/ solutions (accessed on 15 July 2017).

74. Trunkbird. Schicke es über andere Leute. Available online: https://drophub.de/\#/send (accessed on 10 July 2017).

75. Deliv. Available online: http:/ / www.deliv.co (accessed on 17 June 2017).

76. Roadie. How to Ship with Roadie. Available online: https:/ /www.roadie.com (accessed on 10 July 2017).

77. Rogers, H.; Baricz, N.; Kulwant, S.P. 3D printing services: Classification, supply chain implications and research agenda. Int. J. Phys. Distrib. Logist. Manag. 2016, 46, 886-907. [CrossRef]

78. 3D Printing.com. What Is 3D Printing? Available online: http://3dprinting.com/what-is-3d-printing/ (accessed on 26 November 2016).

79. General Electric Inc. 3D Printing Creates New Parts for Aircraft Engines. Available online: http: //www.geglobalresearch.com/innovation/3d-printing-creates-newparts-aircraft-engines (accessed on 10 November 2016).

80. Amazon Locker. Warum Amazon Locker. Available online: https:/ / www.amazon.de/b? node=11498162031 (accessed on 20 July 2017).

81. Fairtransport. From A to B Emission Free. Available online: http://fairtransport.eu (accessed on 17 June 2017).

82. Von der Gracht, H.A.; Darkow, I.-L. Scenarios for the logistics services industry: A Delphi based analysis for 2025. Int. J. Prod. Econ. 2010, 127, 46-59. [CrossRef]

83. Zeithaml, V.A.; Parasuraman, A.; Berry, L.L. Problems and strategies in services marketing. J. Mark. 1985, 49, 33-46. [CrossRef]

84. Leimeister, J.M. Dienstleistungsengineering und Management; Springer: Berlin/Heidelberg, Germany, 2012; ISBN 978-3-642-27983-6.

85. Freightos. Find the Perfect Freight Quote. Available online: https://www.freightos.com (accessed on 20 July 2017).

86. Goldsby, T.J.; Zinn, W. Technology Innovation and New Business Models: Can Logistics and Supply Chain Research Accelerate the Evolution? J. Bus. Logist. 2016, 37, 80-81. [CrossRef]

87. Fu Tsang, N.K.; Lai, M.T.; Law, R. Measuring e-service quality for online travel agencies. J. Travel Tour. Mark. 2010, 27, 306-323. [CrossRef]

88. Hausmann, L.; Rehm, W.; Nangia, I.; Rothkopf, M.; Netzer, T. Pathway to value creation. In A Perspective on How Transportation and Logistics Businesses Can Increase Their Economic Profit; McKinsey \& Company: New York, NY, USA, 2015.

89. Montreuil, B. Toward a physical internet: Meeting the global logistics sustainability grand challenge. Logist. Res. 2011, 3, 71-87. [CrossRef]

90. Cruijssen, F.; Cools, M.; Dullaert, W. Horizontal cooperation in logistics: Opportunities and impediments. Transp. Res. Part E 2007, 43, 129-142. [CrossRef]

91. Daniluk, D.; Holtkamp, B. Logistics Mall—A Cloud Platform for Logistics. In Cloud Computing for Logistics; Hompel, M., Rehof, J., Wolf, O., Eds.; Springer: Cham, Switzerland, 2015; pp. 13-27. ISBN 978-3-319-13403-1.

92. logistics Mall. Die Digitale Lösung für Ihre Logistik. Available online: https://logistics-mall.com/uebersicht (accessed on 1 July 2017).

93. Third-Party Logistics Study. The State of Logistics Outsourcing. Results and Findings of the 21st Annual Study. Available online: http:/ / www.3plstudy.com/3plindex.php (accessed on 25 September 2017). 
94. Davis F.D., Jr. A Technology Acceptance Model for Empirically Testing New End-User Information Systems: Theory and Results. Master's Thesis, Massachusetts Institute of Technology, Cambridge, UK, 1986.

95. Gassmann, O.; Frankenberger, K.; Csik, M. Geschäftsmodelle Entwickeln. 55 Innovative Konzepte Mit Dem St. Galler Business Model Navigator; Hanser Verlag: München, Germany, 2017; ISBN 978-3-446-43567-4.

(C) 2017 by the authors. Licensee MDPI, Basel, Switzerland. This article is an open access article distributed under the terms and conditions of the Creative Commons Attribution (CC BY) license (http:/ / creativecommons.org/licenses/by/4.0/). 